\title{
A satellite-based terrestrial water storage indicator to assess the severity of a heatwave
}

\author{
JOSE AGUSTIN BREÑA-NARANJO \& ADRIAN PEDROZO-ACUÑA \\ Institute of Engineering, Universidad Nacional Autónoma de México, Edificio 5, $2^{\circ}$ piso, Cubículo 306, Ciudad \\ Universitaria, Mexico D.F. \\ jbrenan@ii.unam.mx
}

\section{INTRODUCTION AND OBJECTIVES}

The emergence and development of improved tools for monitoring the occurrence, timing and duration of droughts and heatwaves are very important for water security purposes, with further implications for food security, water quality and hydropower production, among others. Unlike conventional studies that use climate and ecosystem data to assess the impact of droughts and heatwaves on land surface processes occurring at the terrestrial surface (precipitation, temperature and vegetation indexes) or in the shallow layers of the subsurface (soil water content), recent studies have characterized the severity of droughts over large regions $\left(>100000 \mathrm{~km}^{2}\right)$ based on satellite observations of terrestrial water storage variations (Houbourg et al. 2012, Thomas et al. 2014). Such indicators can be used as a proxy to estimate the duration and magnitude of water deficit events. This work proposes a new methodology aimed at describing the variability of water storage deficits over space and time in three regions that suffered prominent dry spells over the last decade: Eastern Russia, the Middle East and the Western Sahel (Fig. 1). To accomplish this objective, we investigate the impact of the 2010 Northern Hemisphere summer heatwave on cumulative terrestrial water storage anomalies detected by the Gravity Recovery and Climate Experiment (GRACE) followed by a space-time aggregation. The concept of water storage deficit as defined by Thomas et al. (2014) is estimated and a deficit-duration-area curve is built for each region.

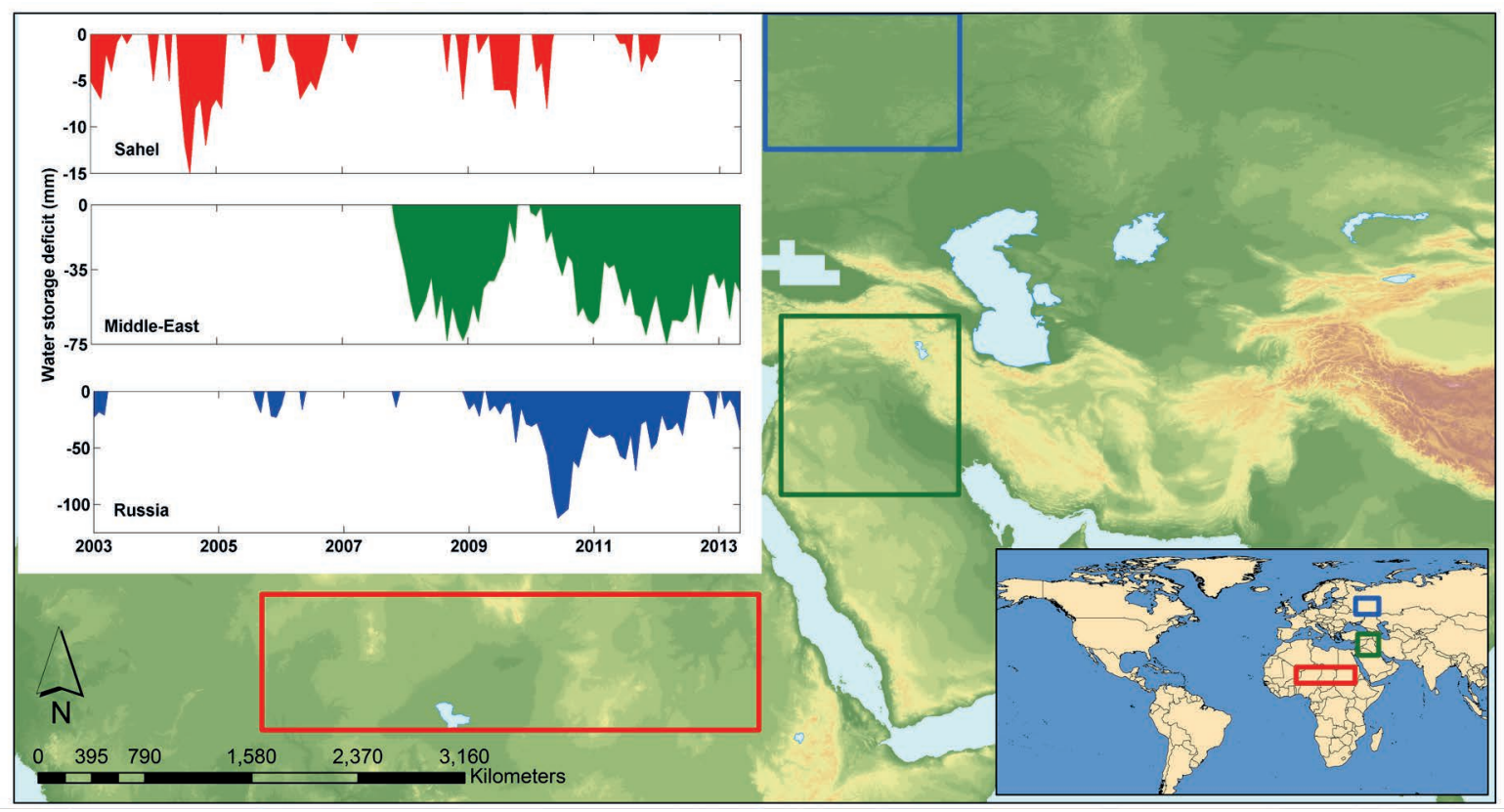

Fig. 1 Location of the study regions: Russia (blue box), Middle East (green box) and Sahel (red box). For the same regions, monthly water storage deficits from 2003 until 2013 are shown in the inner box. 


\section{RESULTS}

Water storage deficits varied greatly in the three regions. The analysis shows that Russia experienced the most severe water storage deficit, followed by the Middle East, whereas Eastern Sahel was not significantly affected. As a result, a set of curves representing different water storage deficits for a given duration and area of the region was obtained (Fig. 2). The curves show the magnitude of the decline and recovery of terrestrial water storage from 1 until 13 months and for spatial extensions ranging between $\sim 10000 \mathrm{~km}^{2}$ and $\sim 250000 \mathrm{~km}^{2}$. Different patterns describing the temporal persistence of deficits for different areas in Russia and the Middle East (convex shape curve) or abrupt changes in storage such as in the Sahel (concave shape curve), suggest that the response of subsurface storage - mainly composed of soil moisture and groundwater storage - to a heatwave can strongly differ.

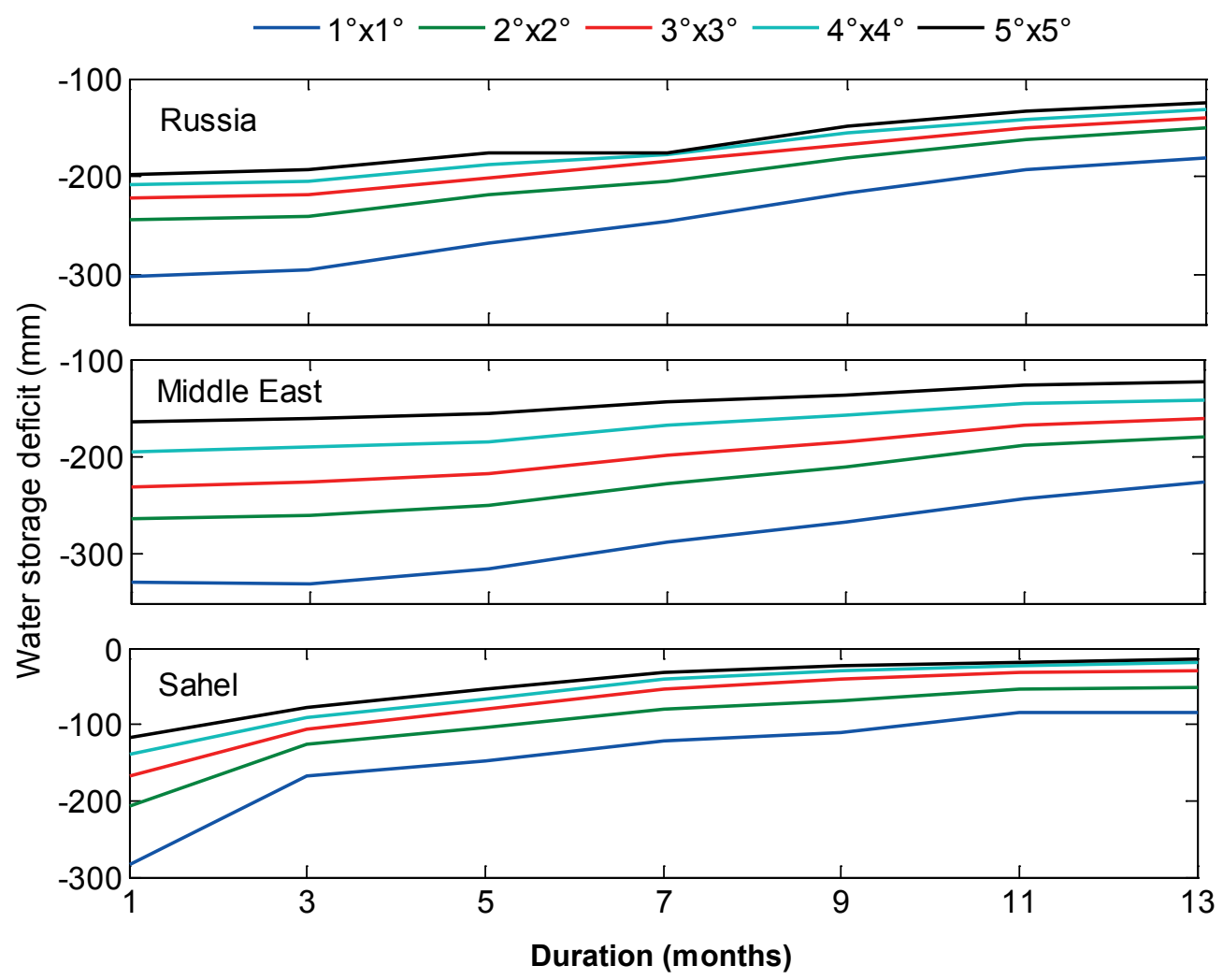

Fig. 2 Water storage deficit-duration-area curves: Russia (top), Middle East (centre) and Sahel (bottom). Storage deficits are displayed on the $\mathrm{Y}$-axis, duration on the $\mathrm{X}$-axis and the coloured lines correspond to different aggregated areas.

\section{CONCLUSIONS}

This work shows how satellite-based observations of terrestrial water storage fluctuations can provide estimates of drought persistence and severity in subsurface hydrological systems. It also demonstrates that the response of terrestrial water storage to heatwaves is stronger in energylimited regions than in water-limited environments. Further work about the propagation of water storage deficits within the hydrosphere due to heatwaves needs to be done.

\section{REFERENCES}

Houbourg, R., et al. (2012) Drought indicators based on model-assimilated Gravity Recovery and Climate Experiment (GRACE) terrestrial water storage observations. Water Resources Research 48, W07525.

Thomas, A.C., et al. (2014) A GRACE-based water storage deficit approach for hydrological drought characterization. Geophysical Research Letters 41, 1537-1545. 